\title{
Eating disorders and childhood obesity: Who are the real gluttons?
}

\section{Joan M. Johnston}

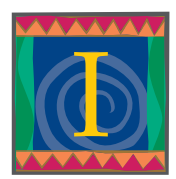

recently received a package in the mail intended as part of an obesity-awareness campaign aimed at family physicians and pediatricians. The materials included body mass index (BMI) charts, worksheets, handouts and a poster. These materials urged me to calculate the BMI of every child in my practice and, for those over the 85th percentile, to set up an "intervention" to give advice and counselling to parents and child - delivered empathically and uncritically, of course.

An apparently limitless supply of these printed materials is available to physicians in my province, the bill being footed by government and professional agencies. The monetary cost of the campaign makes me shudder, but the human cost makes me angry.

As a physician and recovered anorexic who has worked with patients with eating disorders for the past 12 years, I am disgusted by the cavalier disregard for eating disorders exhibited in the medico-cultural war against obesity. The resource materials I received contained not a word about eating disorders. Why this massive blind spot? Are we to believe that obesity is an isolated phenomenon unrelated to eating disorders? Or is the reason more sinister? Are physicians the pawns of a \$50-billion a year diet and fitness industry?' ${ }^{1}$ Or are we being manipulated by health care policy-makers' myopic focus on the bottom line? (As an elected politician recently remarked to me, "In 10 years we will not be able to afford to treat type 2 diabetes in this province!")

It is common knowledge that there is a mounting incidence of obesity in our population. The reasons are many and complex; as we all know, diet and sedentary lifestyles play a part. Virtually every patient I see in my family practice already possesses a surfeit of information about these issues. How could they not, given the obsessive media attention given to diet, exercise and body type?

Is it unreasonable to expect physicians to take a broader and more insightful approach to the problem of obesity than do the publishers of Cosmopolitan, Elle or Men's Fitness? Can we not for a moment stop to consider the implications for our patients if we jump on the weight-loss bandwagon?

Childhood obesity is not unconnected to eating disorders. Indeed, many overweight youngsters are already suffering from an eating disorder (typically binge eating) as the primary cause of their abnormal weight gain. This is known in common parlance as "compulsive overeating" and is characterized by the use of food as a drug to soothe disturbing emotions such as anger, fear or sadness (not unexpected feelings for anyone growing up in today's world). For such individuals, launching a frontal assault on the symptom (obesity) instead of dealing with the underlying cause (the eating disorder) may simply catalyze the transformation of their disorder into anorexia or bulimia nervosa. Diet clubs and exercise facilities are filled with people who for most of their lives have been trying to control their bodies without ever being diagnosed as having an eating disorder. Their physicians are as oblivious or deluded as they are.

For young people who are overweight because of lifestyle factors or underlying metabolic or genetic conditions, this campaign also completely ignores the reality that most cases of anorexia and bulimia originate in early or mid-adolescence in individuals with a fragile sense of self and a core belief that life is uncontrollable (which it is). Food, exercise and body weight then become the arena in which they can establish a feeling of control over their lives. Too late, they discover that this "control" is mere illusion, that they have lost all power of choice over their eating and exercise behaviours and simply cannot stop. Up to $20 \%$ of them will die from their eating disorder, ${ }^{2}$ a number far higher than the risk of death from diabetes or heart disease related to obesity.

Undoubtedly, childhood obesity is a serious problem in our country that needs to be addressed - but with creativ-

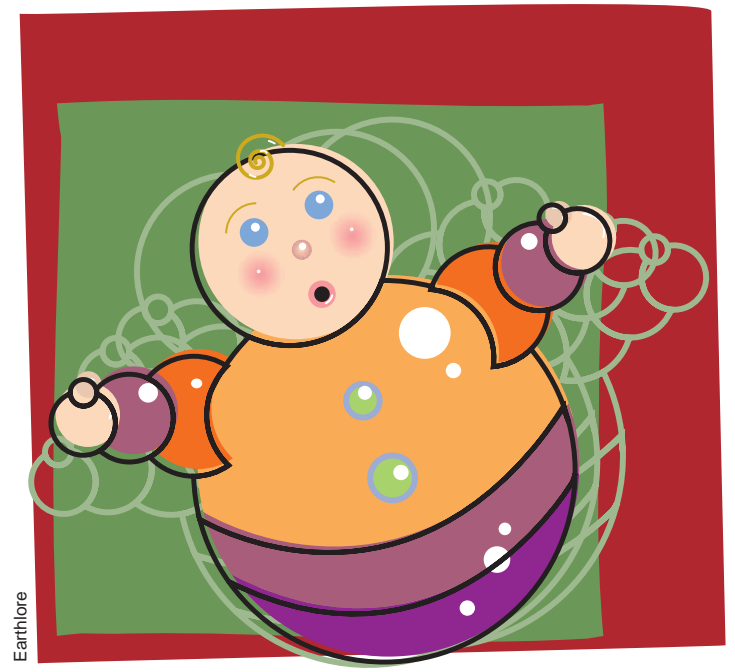


ity and imagination, not with reflexive and heavy-handed strategies. Einstein once said, "Imagination is more important than knowledge." "Until we dare to imagine the real causes of this multifaceted problem, until we stop racing for a quick fix and instead tune in to the personal unhappiness, the profound dissatisfaction with life, that lies at its root, then we are doomed to go on seeing the problem as a mathematical equation in which the variables are caloric intake and expenditure.

I can't think of a better way to damage the self-esteem of children than to tell them, tactfully or otherwise, that their bodies are overfed or underexercised. By adding the official voice of family physicians and pediatricians to the consumerist messages already bombarding them about diet and exercise, we will be endorsing the exploitative purveyors of these messages. We will be telling our kids that they are not okay, and we will drive many of them into the waiting arms of anorexia and bulimia.

Theologian and historian Matthew Fox has characterized our society as one that "devours its youth." "This is a strange cultural pathology indeed.

Joan Johnston is a family physician in Edmonton, Alta.

\section{References}

1. The Eating Disorder Education Organization, www.edeo.org (accessed 2004 Nov 15).

2. Ratnasuryi RH, Eisler I, Szmukler GI, Russell GFM. Anorexia nervosa: outcome and prognostic facts. Br 7 Psych 1991;158:495-502.

3. Desroches L. Allow the water. Toronto: Dunamis Publishers; 1996. p. 172.

4. Fox M. The coming of the cosmic Christ. San Francisco: HarperCollins; 1988. p. 181

\section{A survey of entertainment extremes among medical students in Croatia}

\section{Svjetlana Dolovร̌ak, Davorka Dušek, Darko Hren, Ana Marušić, Matko Marušić}

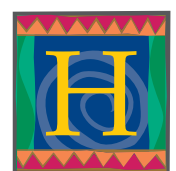

ow do medical students spend their free time? Are they overindulging in any sort of entertainment? Are there any predictors of the entertainment choices they make? An anonymous, voluntary questionnaire survey of medical students in Zagreb, Croatia, yielded some important results. It seems that appreciation for a drunken state and lower inner motivation will take students to a disco club, whereas the perception of having little free time will keep them at home, especially if they are male. Students who choose going to the theatre as the only sort of fun to have seem to be nonsmokers and nondrinkers, who have just enough free time ...

All authors are from the Zagreb University School of Medicine, Zagreb, Croatia. Svjetlana Dolov and D. DuSek are fifth-year students of the Zagreb University School of Medicine.

\begin{tabular}{|c|c|c|}
\hline \multicolumn{3}{|c|}{ Predictors of students' extreme choices of entertainment in their free time } \\
\hline $\begin{array}{l}\text { Extreme choice } \\
(N=687)\end{array}$ & Predictors for extreme choice & Odds ratio $(95 \% \mathrm{Cl})$ \\
\hline \multirow{3}{*}{$\begin{array}{l}\text { Stay home all the time } \\
(n=47) \text { (see Fig. A) }\end{array}$} & Male sex & $2.11(1.02-4.35)$ \\
\hline & Perception of having less free time & $1.43(1.10-2.01)$ \\
\hline & Gets drunk less often & $2.68(1.40-5.13)$ \\
\hline \multirow{3}{*}{$\begin{array}{l}\text { Go to disco club only, } \\
>20 \text { times/yr }(n=75) \\
\text { (see Fig. B) }\end{array}$} & Gets drunk more often & $2.45(1.59-3.78)$ \\
\hline & Lower inner motivation & $1.10(1.05-1.16)$ \\
\hline & Lower GPA & $1.14(1.04-2.47)$ \\
\hline \multirow{4}{*}{$\begin{array}{l}\text { Attend theatre only } \\
(n=50) \text { (see Fig. C) }\end{array}$} & Has not failed a year & $2.26(1.13-4.52)$ \\
\hline & Perception of having more free time & $1.53(1.10-2.15)$ \\
\hline & Gets drunk less often & $3.04(1.56-5.95)$ \\
\hline & Does not smoke & $3.40(1.11-11.76)$ \\
\hline
\end{tabular}

Note: $\mathrm{Cl}=$ confidence interval, $\mathrm{GPA}=$ grade point average.
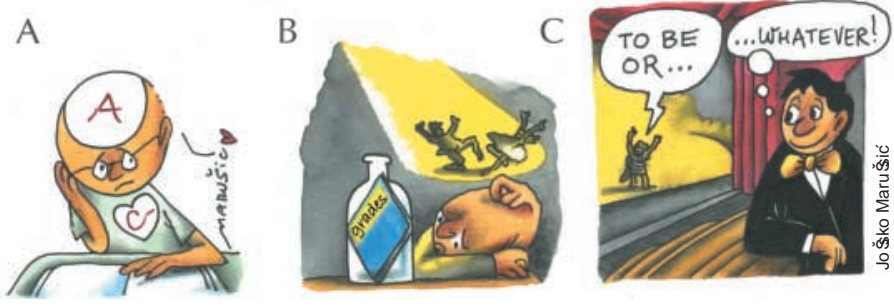